\title{
الاليات الوطنية التنفيدية لحماية حقوق الانسان
}

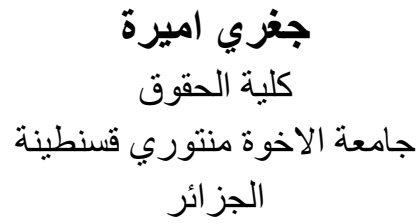

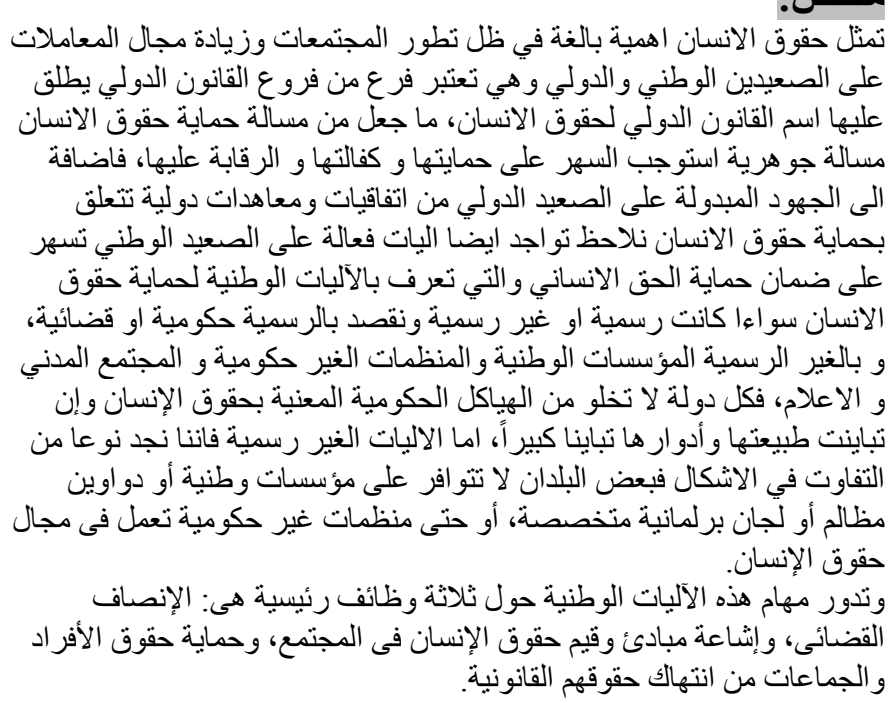

\begin{abstract}
مقدمة: Abstract:
يرى مختلف المرتمون

The human rights represents a great signification of the development of societies and increase of the area transactions on the national and international levels and it is considered as a branch of international law known as the international law of human rights what has made the protection of human rights fundamental requires to be protected guaranteed and controlled, In addition to efforts at the international level of the international conventions and treaties relating to the protection of human rights Also note the presence of effective mechanisms at the national level ensures the protection of human right known as national protection mechanisms of the human rights whether it is formal or informal, we mean by formal governmental or judicial and we mean by informal the national institutions, the civil society and media, So every state is not without governmental structures of human rights but differentiated nature and roles vary considerably, Concerning Informal mechanisms we find a kind of variation in forms, Some countries do not have national institutions or collections of grievances or Specialized parliamentary committees or even non-governmental organizations working in the field of human rights.

The spin of these national mechanisms tasks around three main functions: judicial fairness, to promote the principles and values of human rights in society, and to protect the rights of individuals and groups from violating their legal rights.
\end{abstract}




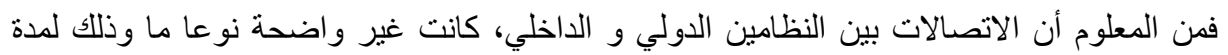

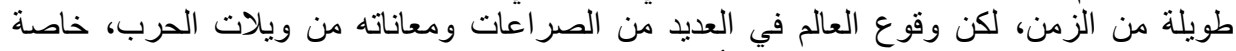

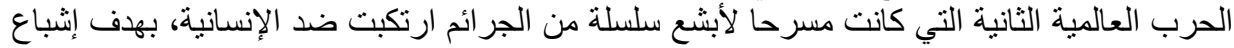

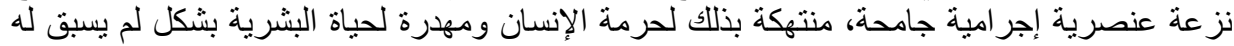

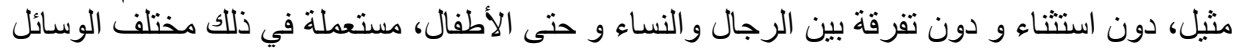

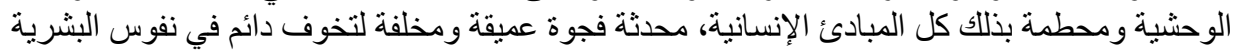

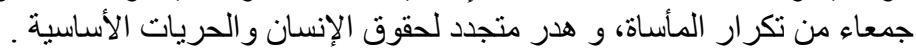

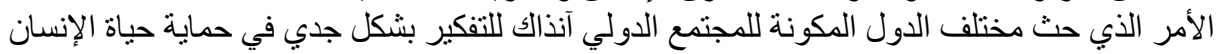

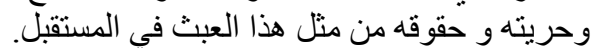

وقد مهد لذلك ميثاق الأمم المتحدة حينما ذكر في ديباجته :((إن شعوب الأمم المتحدة تؤكد إيمانها بالحقوق الأساسية للإنسان و بكر الأنة الفرد)(). وما نص عليه هذا الميثاق من اتجاه الهيئة إلى احترام الإن حقوق الإنسان و الحريات الأساسية للناس جميعا بلا تمييز بين الجنس أو اللغة أو الدين وبلا تفريق بين الرجال و و النساء وحق الثنان الثعوب في تقرير مصير ها.

وبذلك أصبحت المسائل المتعلقة بحقوق الإنسان وحق هذه الثعوب تخرج عن نطاق الأمور المنصلة

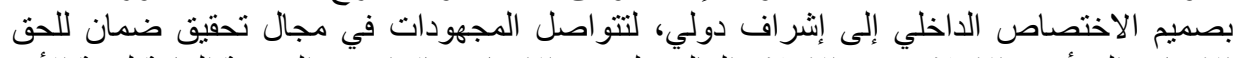

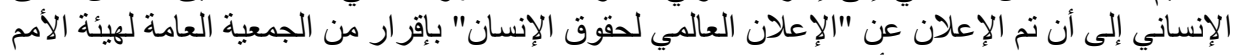

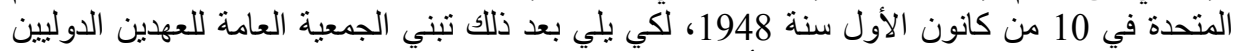

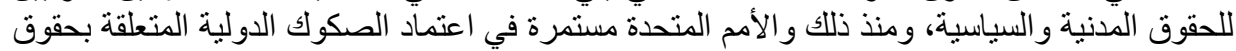
الإنسان وذلك ضمن مبادئ القانون الدولي العام. 2

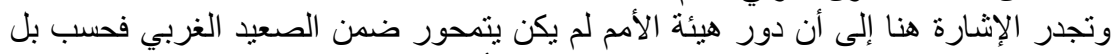

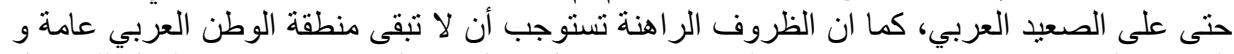

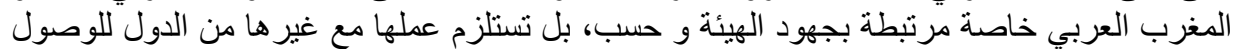

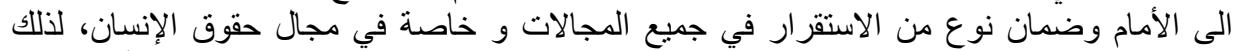

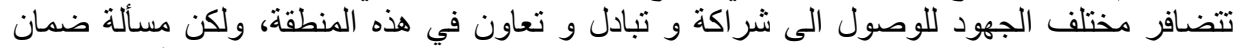

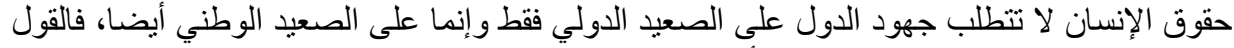

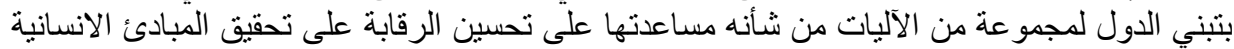

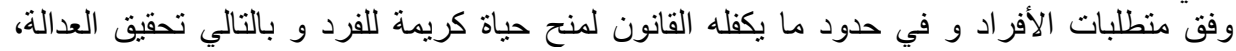

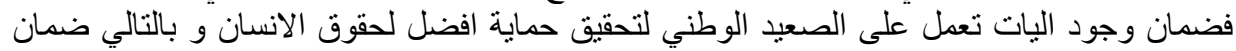

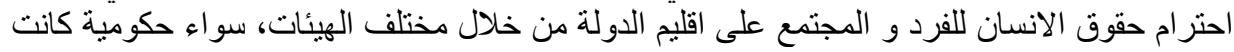

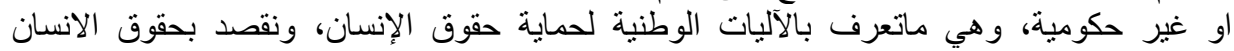

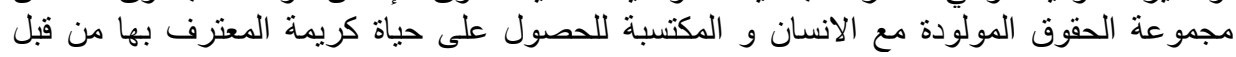

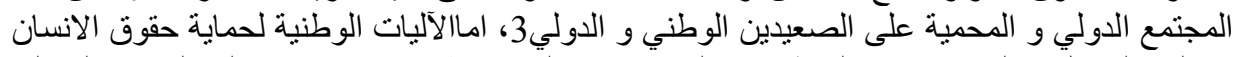

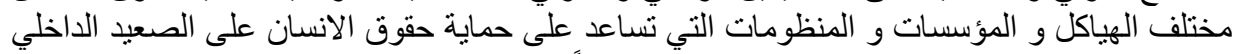

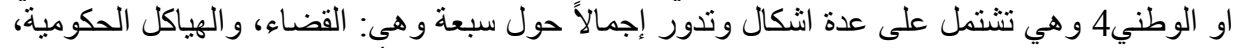

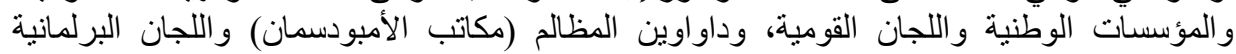
و والمنظمات غير الحكومية، و الإعلام.5

ما يجعل موضو عنا يدور حول الاشكالية التالية 
فيما تتمثل الآليات الوطنية التنفيذية القائمة على حماية حقوق الانسان؟ و مامدى فعاليتها في تحقيق

الحمايةة؟ فيمائ

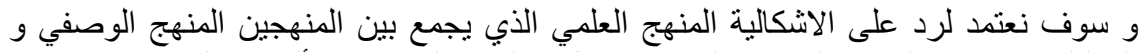

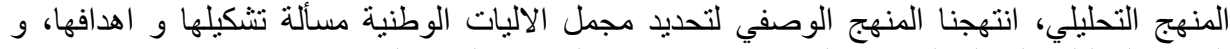

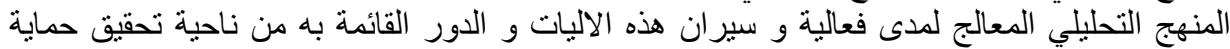

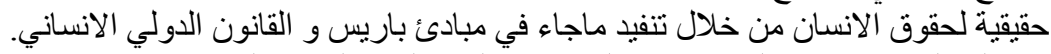

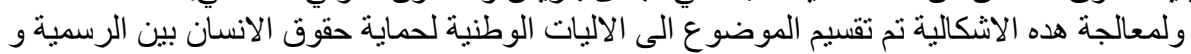

الغير رسمية.

\section{المطلب الاول- الآليات الوطنية الرسمية لحماية حقوق الإنسان}

لا يخلو بلد فى العالم من الآليات الوطنية لحماية حقوق الانسان سو اءا كانت حكومية او قضائية،

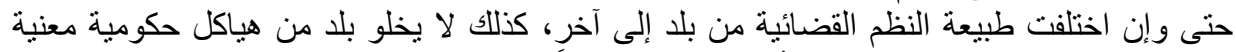

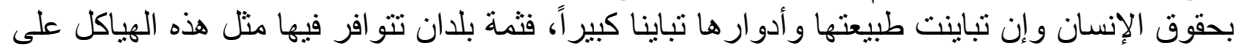

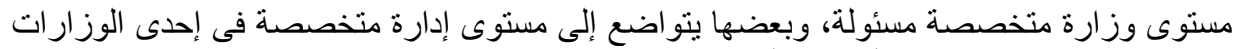

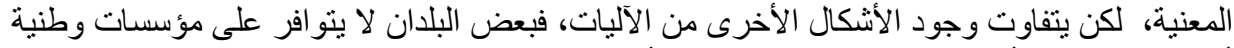

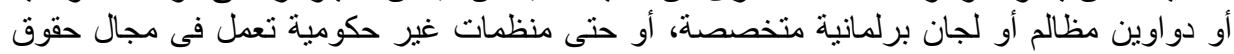

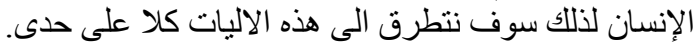

\section{الفرع الاولــ الآليات الحكومية لحماية حقوق الإنسان:}

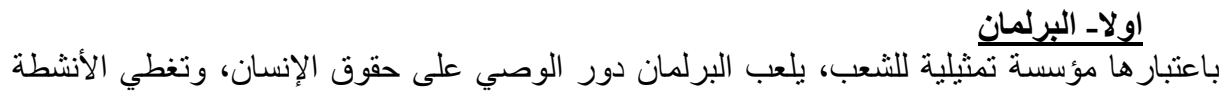

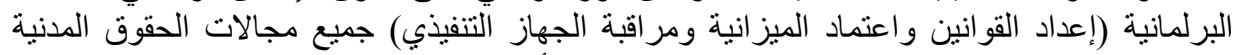

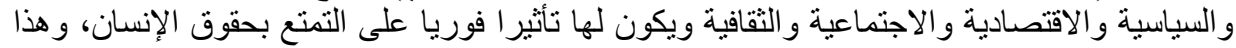

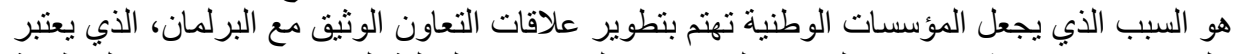

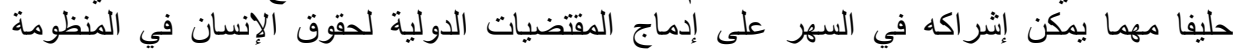

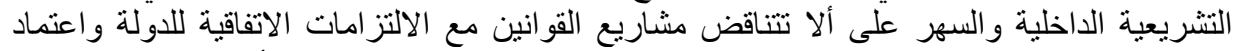

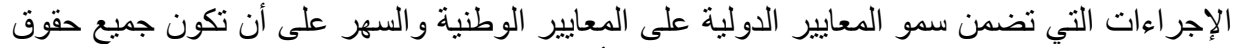

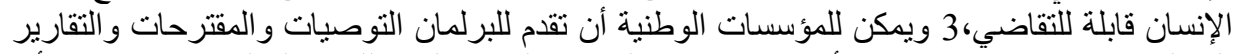

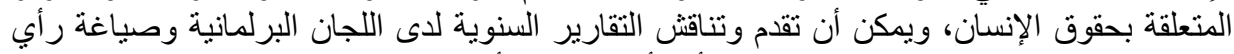

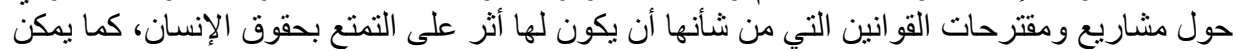

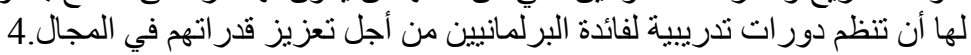

ثانيا/ اللجان البرلمانية المعنية بحقوق الإنسان:

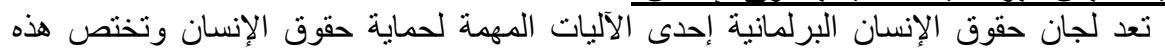

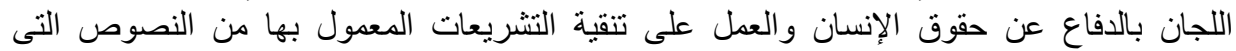

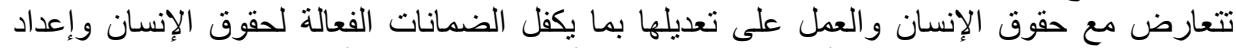

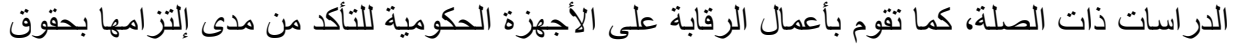

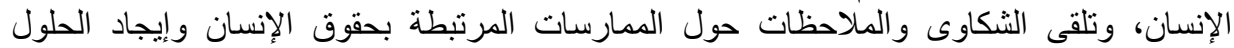
المناسبة لها، كما تقوم بتشكيل لجان تقصى الحقائق فى موضو عات التهات اختصاصها، وتعقد جلسات استماع حول بعض الموضو عات. 


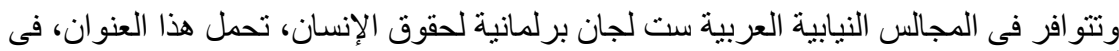

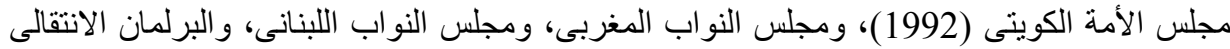

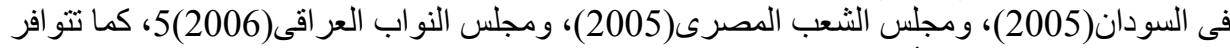

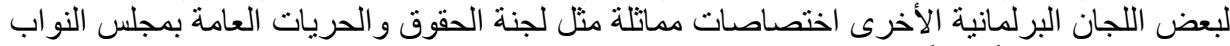

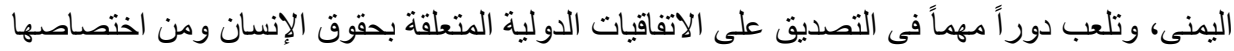

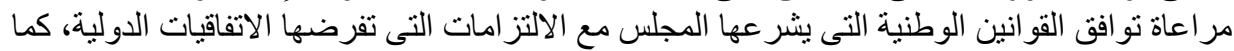

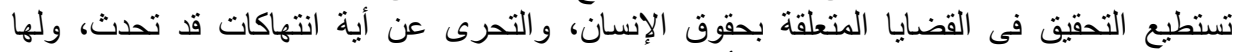

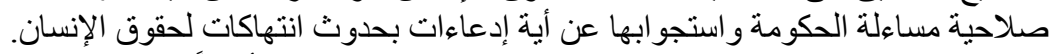

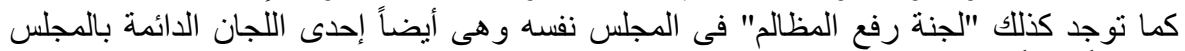

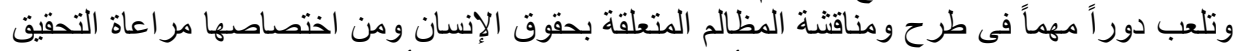

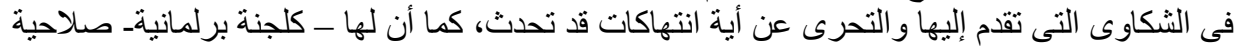

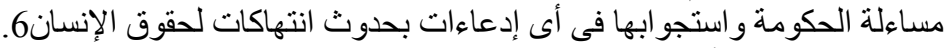

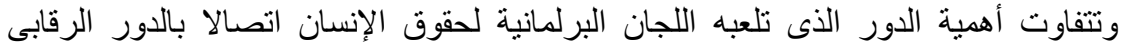

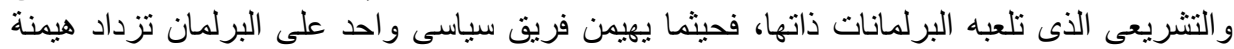

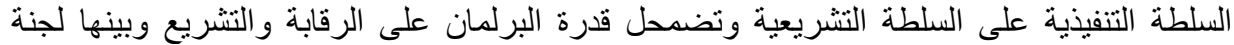

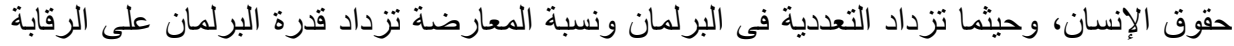

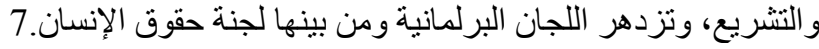

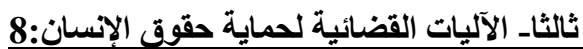

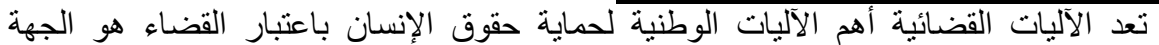

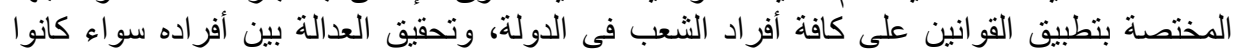
حكاماً أو محكومين.

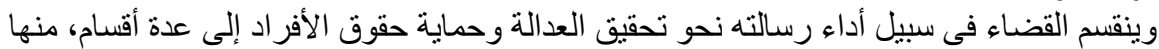

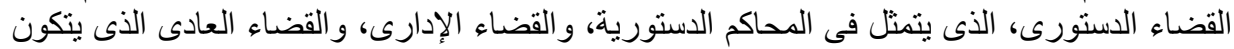

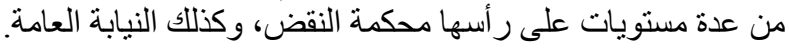
وتختص المحاكم الدسنورية بالرقابة القضائية على دستورية القوانية انين و اللو ائح و الفصل فى تنازع

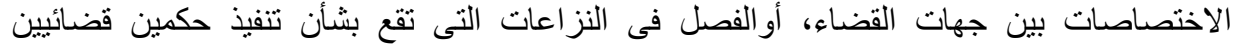

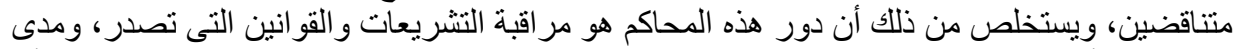

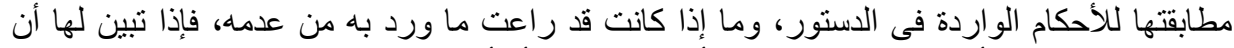

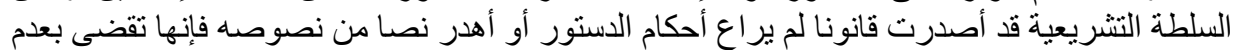

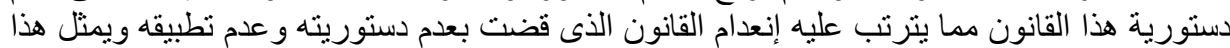

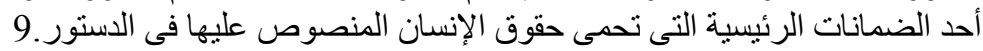

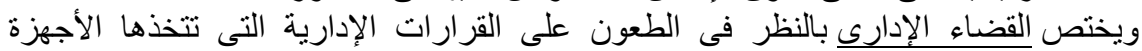

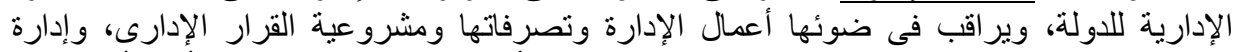

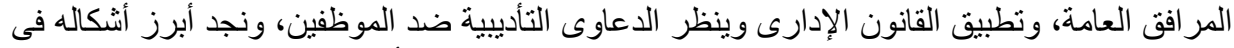

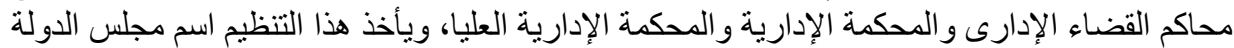

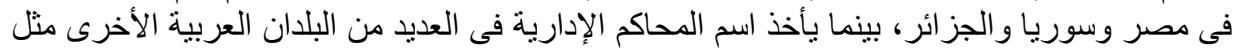

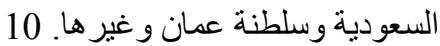

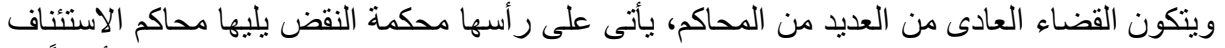

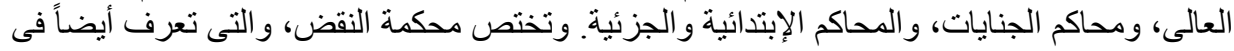

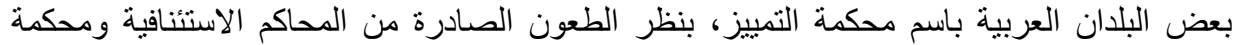
الجنايات، والتى يكون مرجعه الخطأ فى تطبيق القانون أو تفسيره أو تأويله، وكذللك القصور في تسبيب 
الأحكام أو الفساد فى الاستدلال، أو الإخلال بحق الدفاع. وهى تعد خير حماية لضمان حقوق الأفر اد نحو

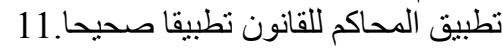

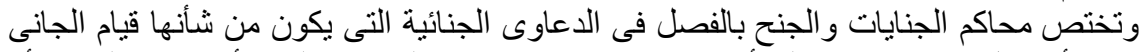

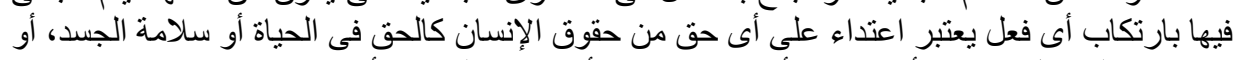

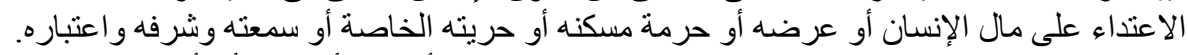

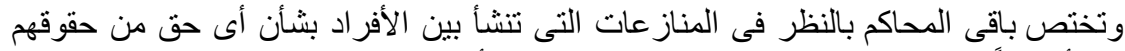

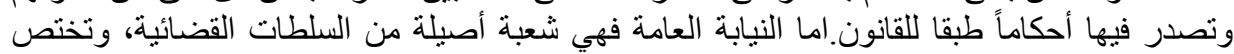

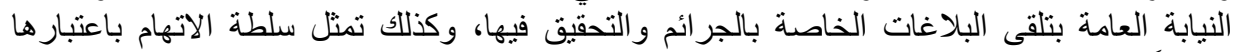

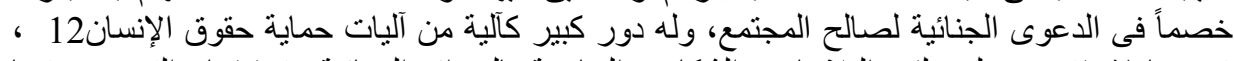

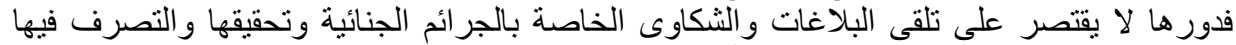

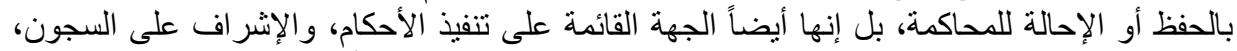

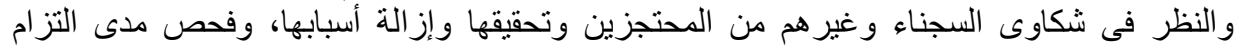

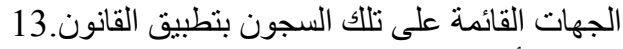
و أبرز هذه العوامل هى نقص استقلال السلطة القضائية، فعلى الرغم من تأكيد الدساتير العربية

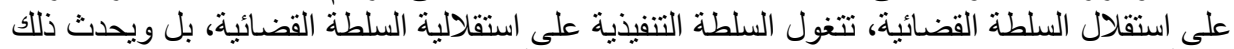
أحياناً من جانب السلطة التشريعية، وتقصر الإمكانيات أحياناً عن تنفيذ أحكام القضاء.

\section{الفرع الثانى- الاليات الغير رسمية لحماية حقوق الانسان}

اولا- المؤسسات الوطنية:14

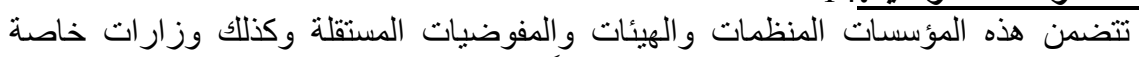

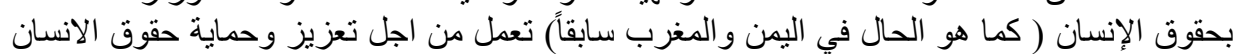
فيذلك البلد

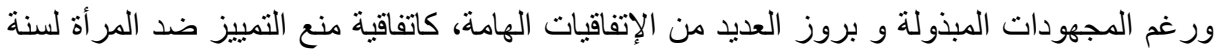

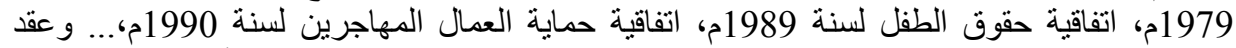

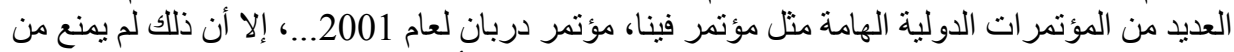

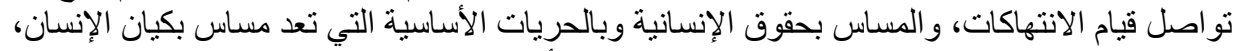

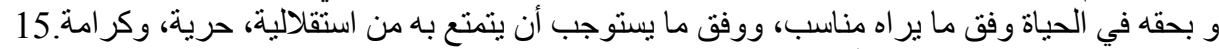

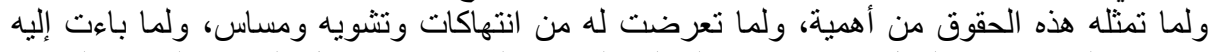

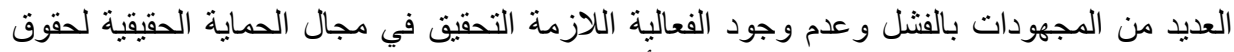

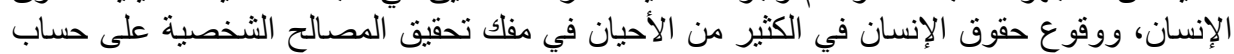

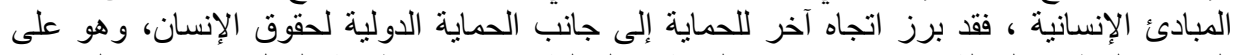

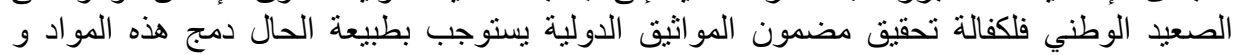

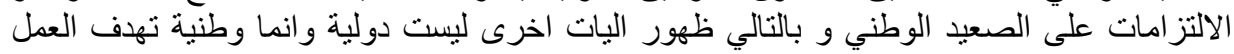

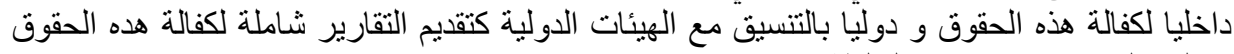

داخليا على جميع مستو يات السلطة. 16

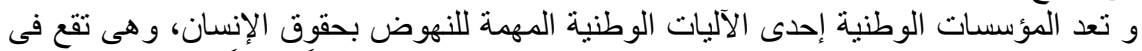

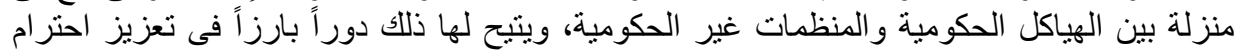

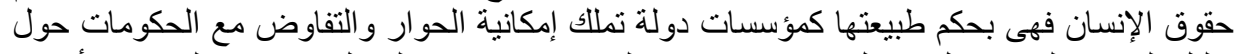

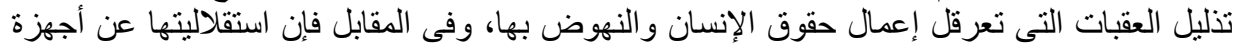

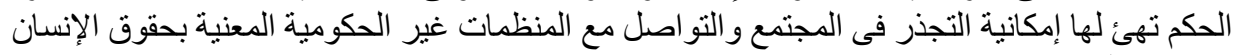

ودعم مطالبها فى تعزيز احتر ام حقوق الإنسان. 17 
ويتم إنشاء هذه المؤسسات بموجب نص دستورى، أو قانون يصدر عن المجلس التشريعى للدولة،

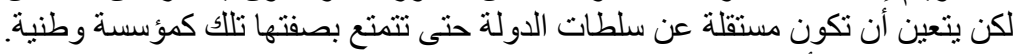

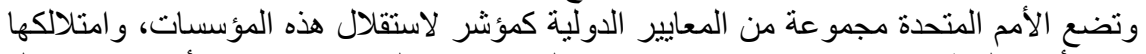

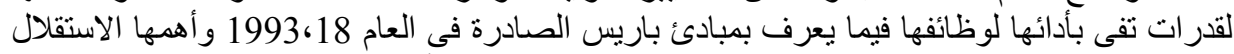

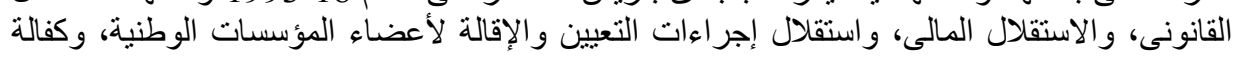

وتتمثل مهام المؤسسات الوطنية فى نشر ثقافة حقوق الإنسان فى المجتمع وملائمة التشريعات التعددية في تشكيلها.

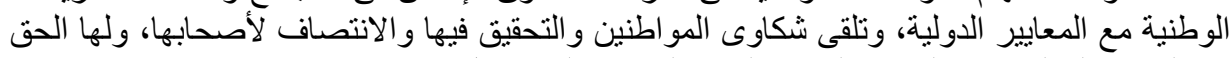

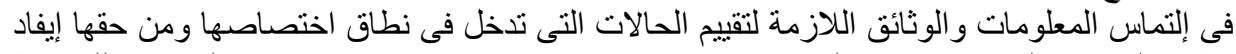

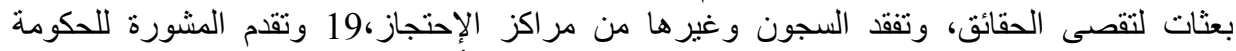

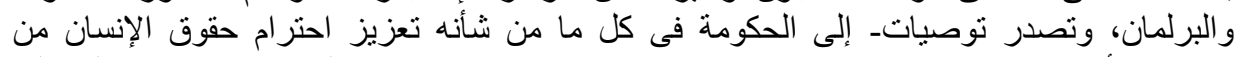

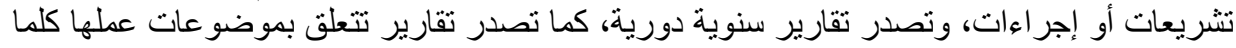

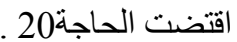

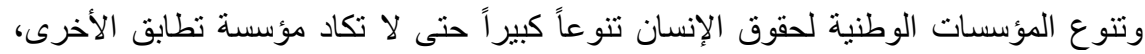

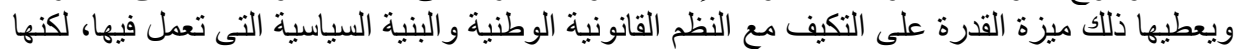

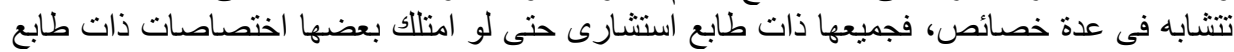

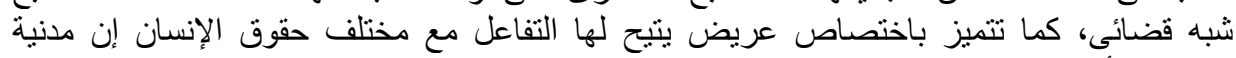
وسياسية، أو اقتصادية واجتماعية وتثافية.

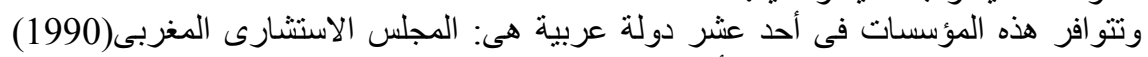

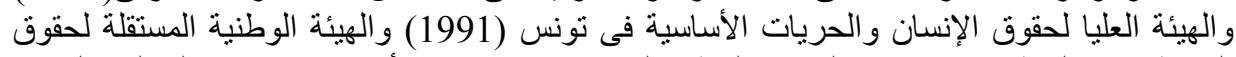

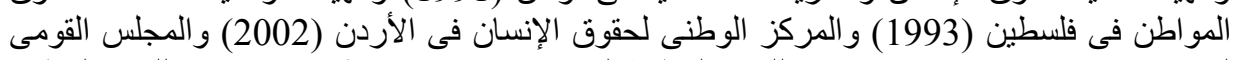

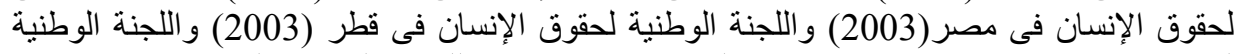

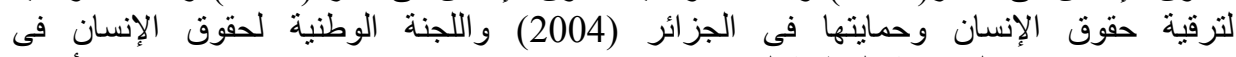

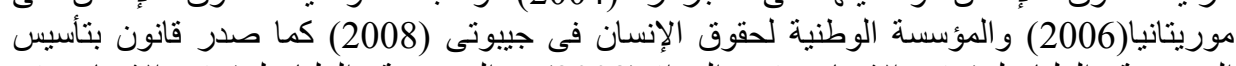

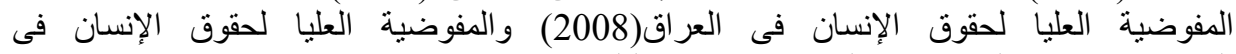

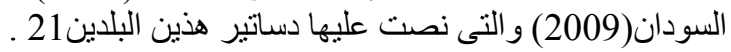

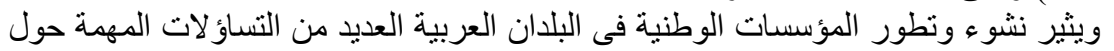

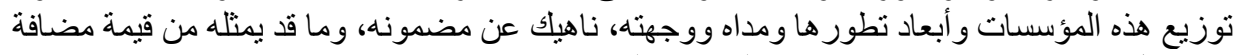

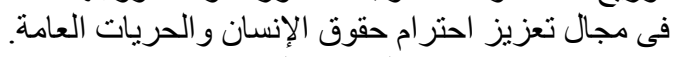

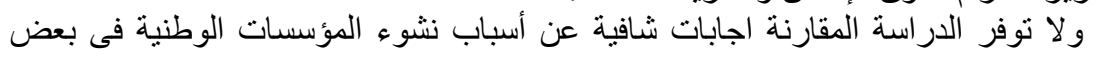

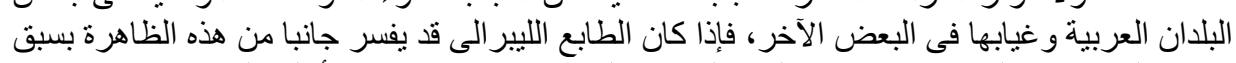

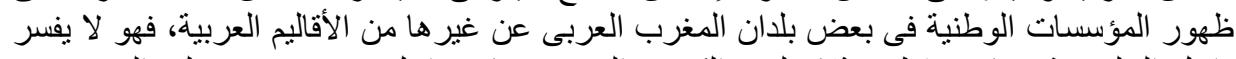

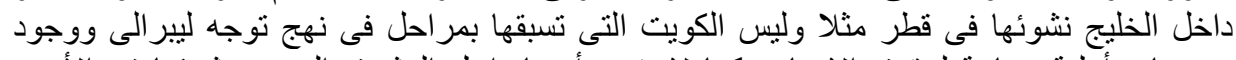

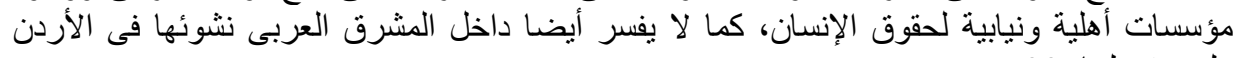

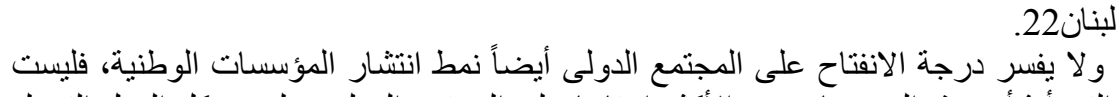

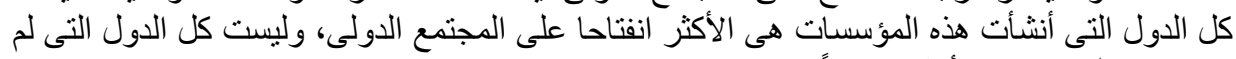
تنشئ هذه المؤسسات الأكثر إنغلاقاً..

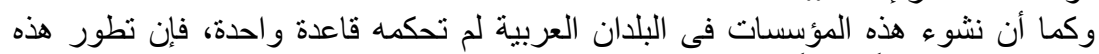

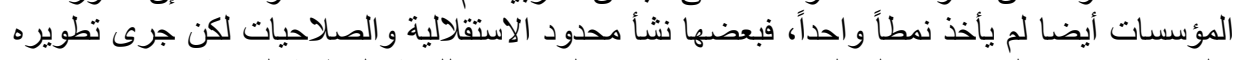

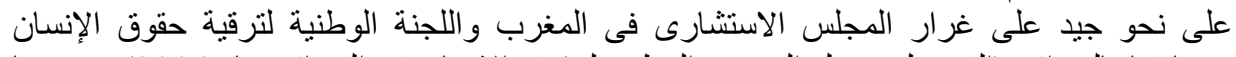
وحمايتها بالجز ائر (التى حلت محل المرصد الوطنى لحقوق الإنسان فى الجزائر عام الإن 2004) وبعضها 
نشأ محدود الاستقلالية و الصلاحيات لكنه بقى على نحو ما بدأ مثل الهيئة العليا لحقوق الإنسان و الحريات

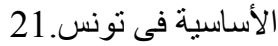

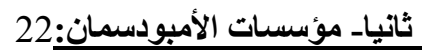

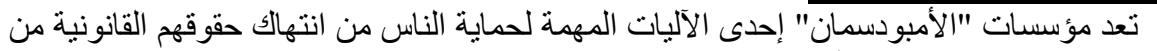

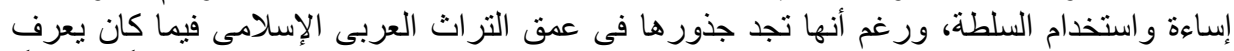

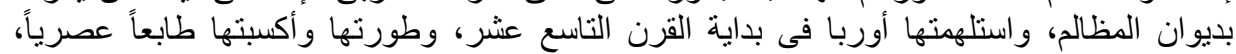

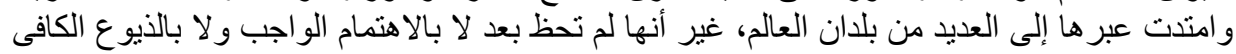

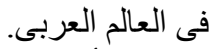

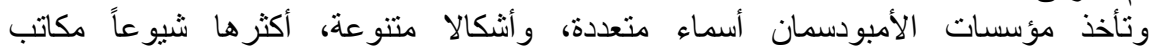

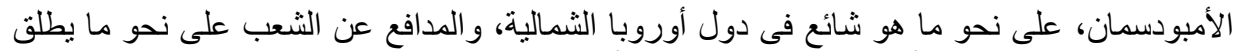

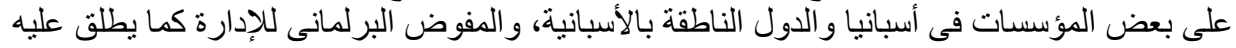

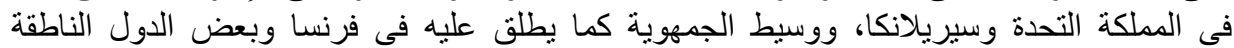

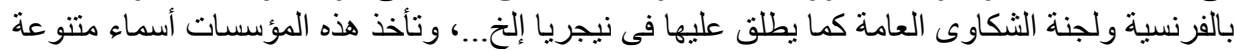
على الساحة العربية هى: ديوان المظالم، والموفق الإدارى، ووسيط الجمهورية، والهيئة العامة العياهة

كذللك تتتوع أثنكال هذه المؤسسات و وأطرها القانونية، وهياكلها التنظيمية ووظائفها

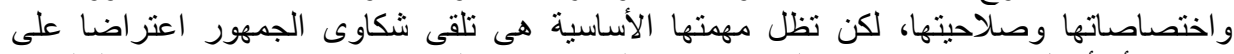

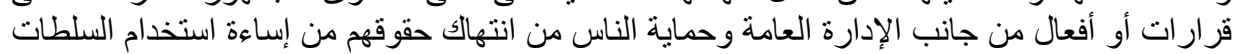

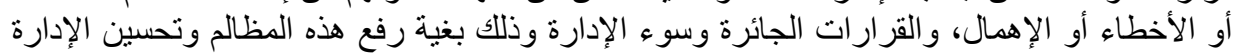

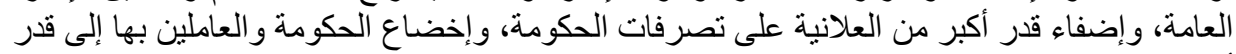

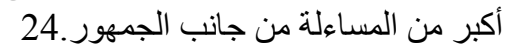

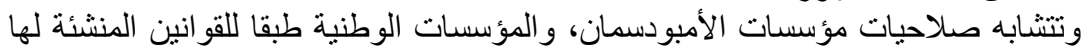

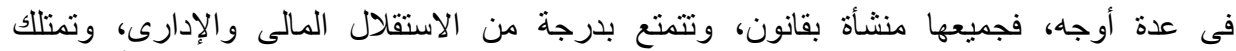

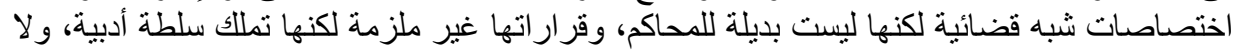

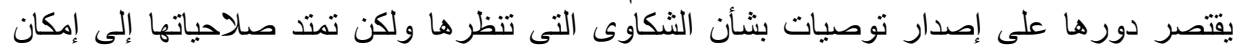

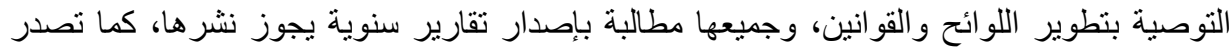
تقارير خاصة ببعض الحالات التى نظرتهانئ

ثالثاء المنظمات الغير حكومية

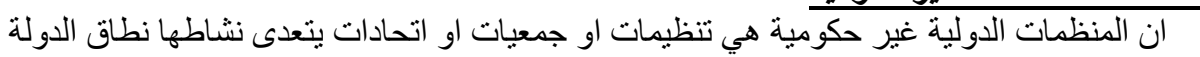

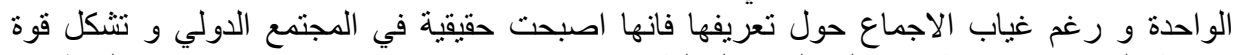

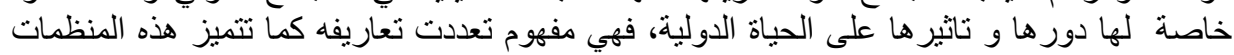

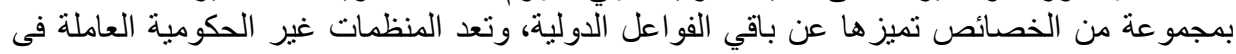

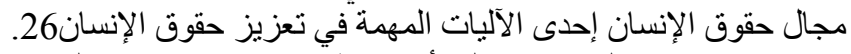

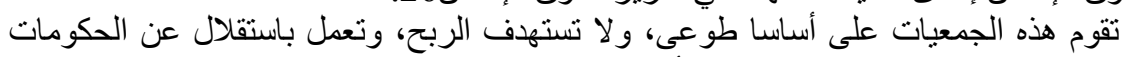

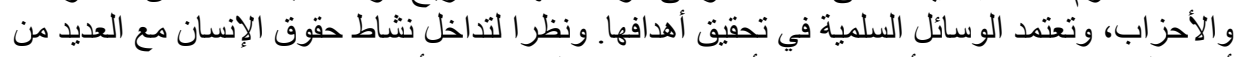

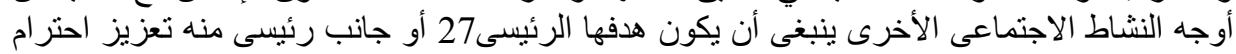
حقوق الإنسان، حتى يمكن تصنيفها بين منظمات الأني حقوق الإنسان.

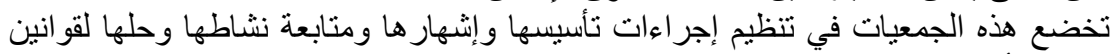

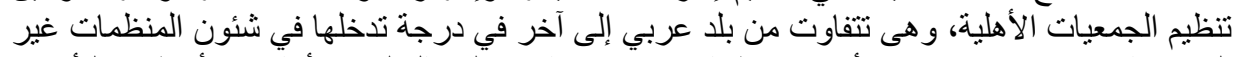

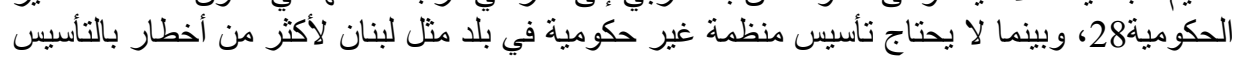


يعرف باسم "علم وخبر" تحتاج في الكثير من البلدان لإجر اءات مطولة، وتتندل جهة الإدارة في شئون

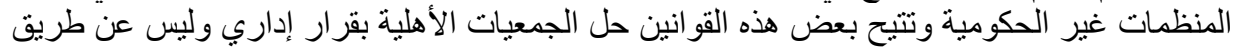

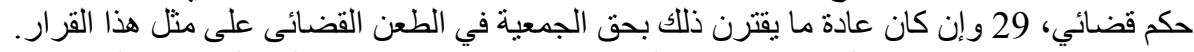

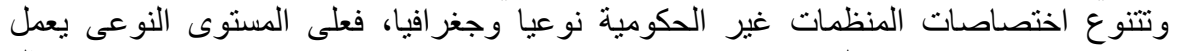

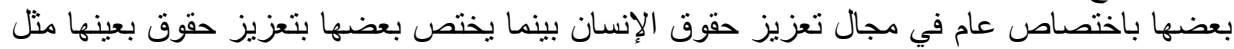

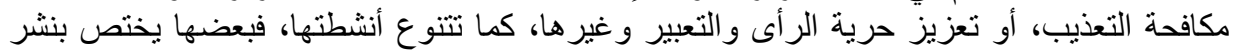

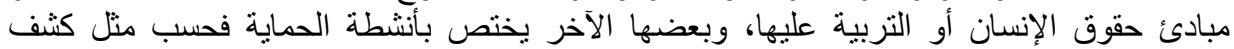

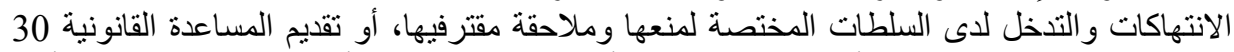

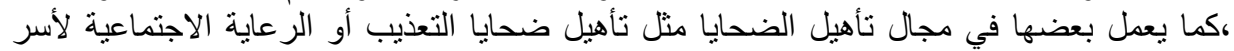

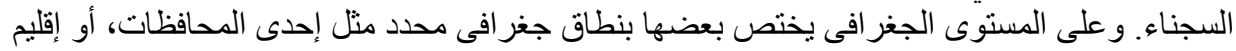

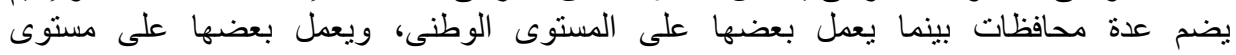

كذلك يتتوع اهتمام المنظمات غير الحكومية العاملة فى مجال حقوق الإنسان بالفئات إقليمى.31 - إنم

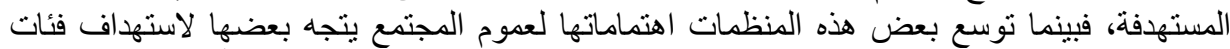

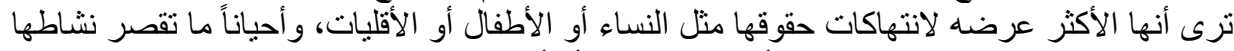

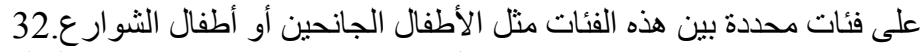

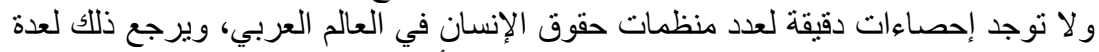

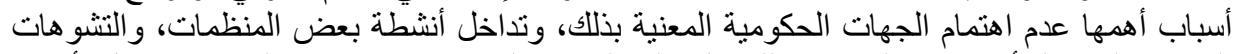

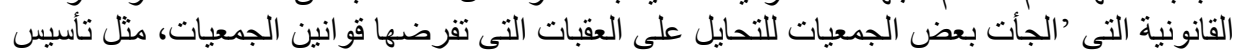

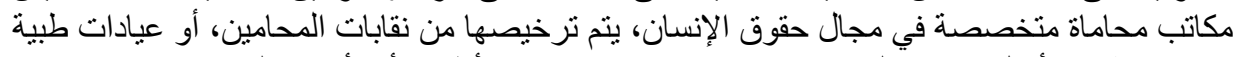

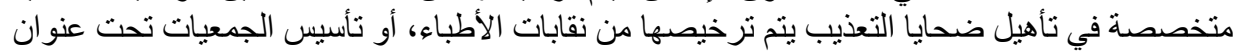

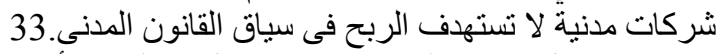

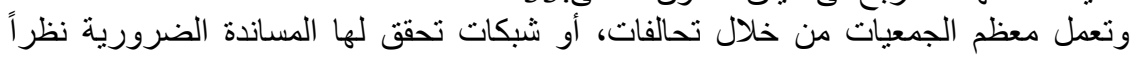

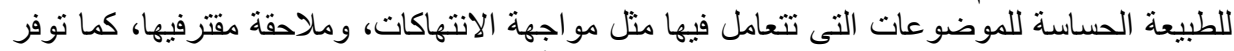
لها تقاسم الخبرة و المعلومات، ودعم الحملات المشتركة للتأثير على السباسات العقابية 34 ـ.

\section{رابعا- وسائل الإعلام}

تلعب وسائل الإعلام دوراً حاسماً في التأثير على مسار حقوق الإنسان ليس فقط من خلال

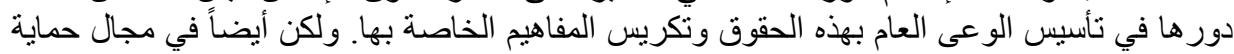

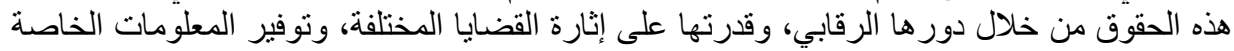
ويعتبر الإعلام والنظام الاتصالى عموماً من أهم آليات عمل حقوق الإنسان، ويتحقق هذه إنهان بها ومتابعتها.

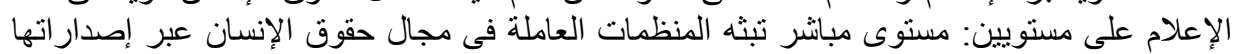

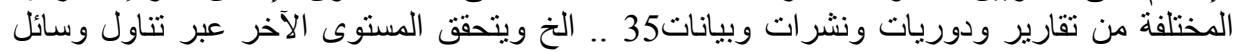
الإعلام الجماهيرية لرسالة حقوق الإنسان وتعد التقارير الدورية أبرز إلصدارات إندات الإعلام المتخصص في مجال حقوق الإنسان ويصدر

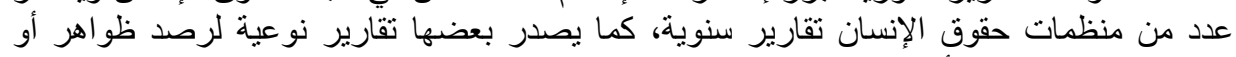

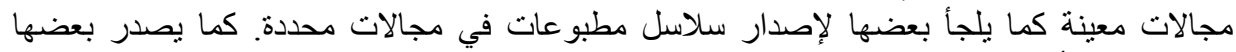

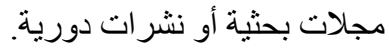

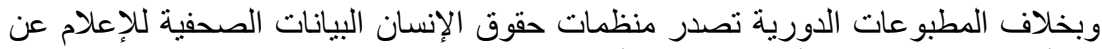
نتائج تحقيقاتها أو در اساتها الميدانية أو الإعلام عن أنشطنها المختلفة الانسان 


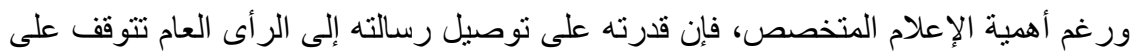

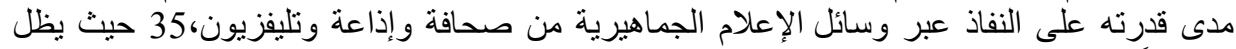

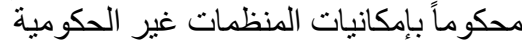

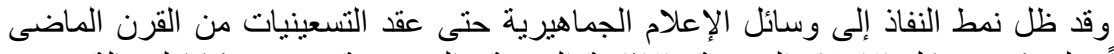

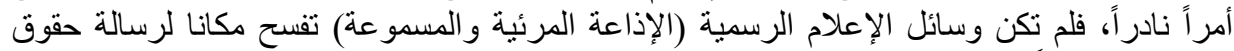

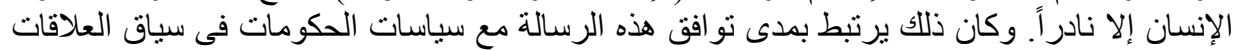

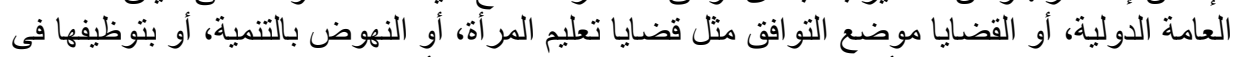

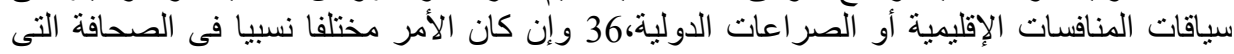

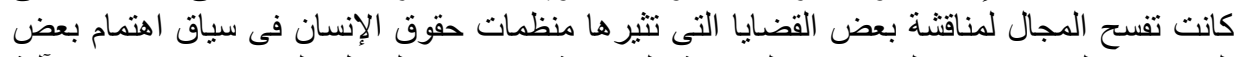

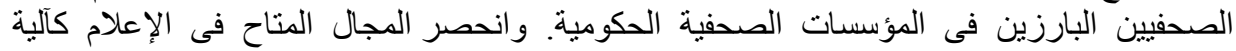

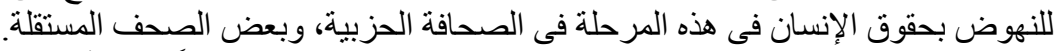

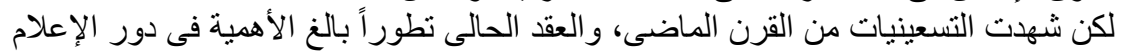

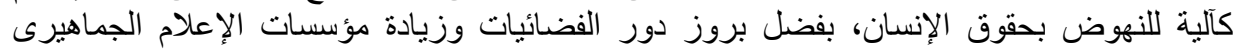

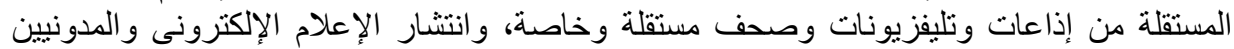

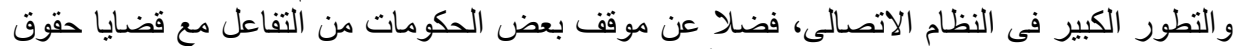

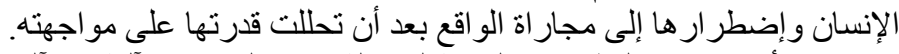

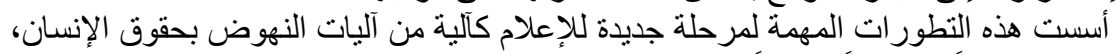

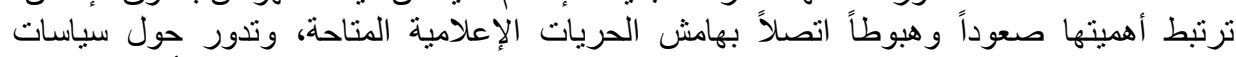

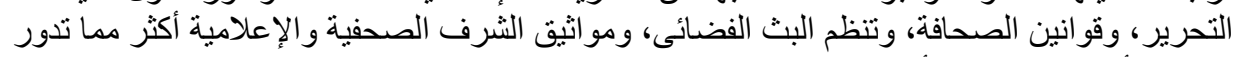
حول مبدأ النشر الصحفى أو البث الإعلامى فى مجال حقوق الإنسان.37.

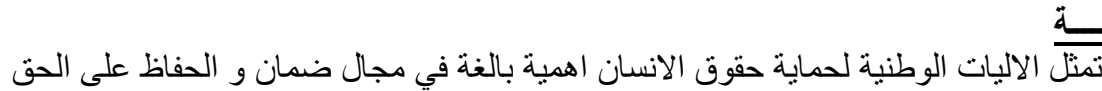
الخاتم

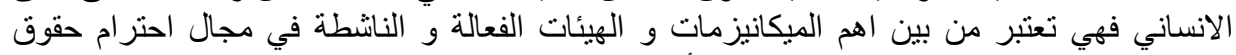

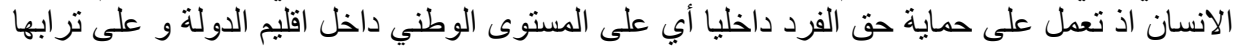

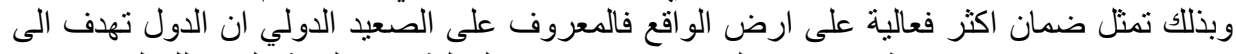

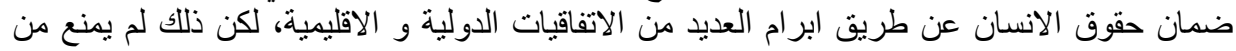

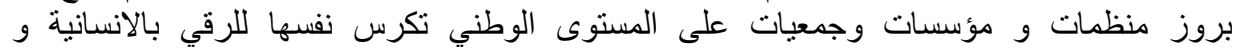

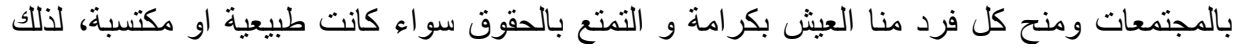

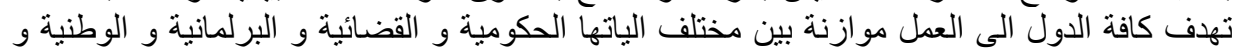

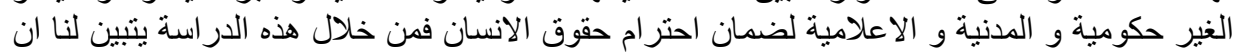

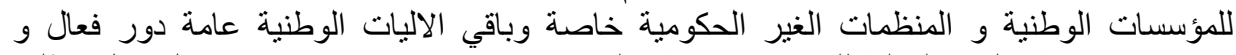

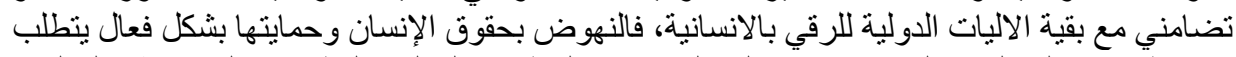

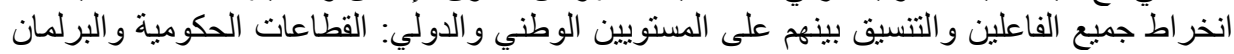

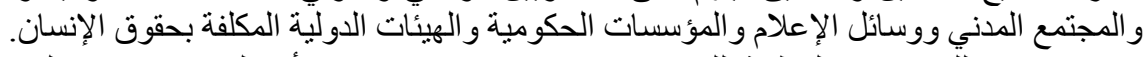

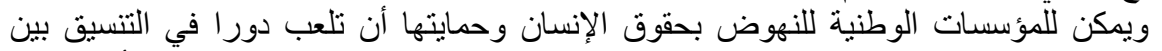

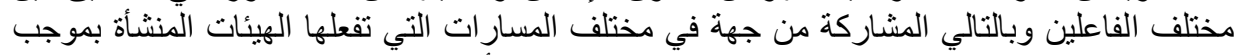

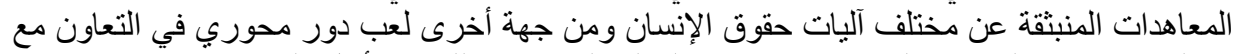

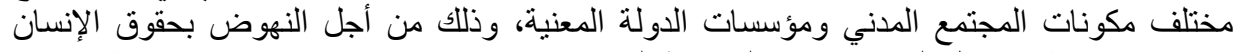
وحمايتها خاصة في دول البحر الابيض المدتوسط التي تنتوع سياساتهاو قدر اتهاو المكانباتهاو ثقافتها. 


\section{-}

1- العودة إلى ديباجة ميثاق هيئة الأمم المتحدة.

2- الإعلان العالمي لحقوق الإنسان لسنة الإنة 1948.

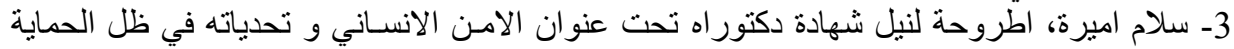

الدولية لحقوق الانسان، كلية الحقوق و العلوم السياسية، جامعة الحاج لخضر الانية باتنة، السنة الجامعية

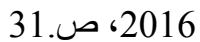

4- مجلة هيئة الامم المتحدة، المؤسسات الوطنية لحقوق الانسان، العدد اربعة من سلسلة التذريب صناب

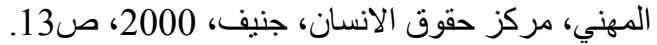

5- إسماعيل معراف، الوضع الاقليمي العربي في ظل المتغيرات الدولية، المؤسسة الوطنية للاتصال ،

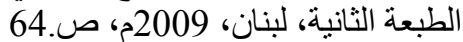

6- محمود شاكر سروود، ناثط في مجال حقوق الانئ الانسان ونانشط في وسائل الاعلام، مجلة حقوق

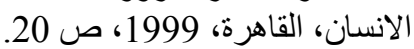

7 - سعاد محمد الصباح، حقوق الإنسان بين النظرية والتطبيق، دار سعاد الصباح، الطبعة الأولى،

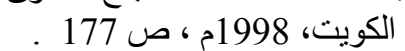
8- أحمد يوسف القرعي، مواثيق حقوق الإنسان السياسية والدولية، مركز الدراسات، الطبعة الأولى،

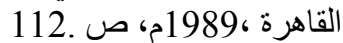
9- خليل حسن، قضايا دولية معاصرة، دار المنهل اللبناني، منشورات الحلبي، بيروت، 2009م.، ص

10 - الدكتور: محد أمين الميداني، القانون الدولي الإنساني وحقوق الإنسان، الطبعة الثالثة،

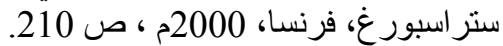

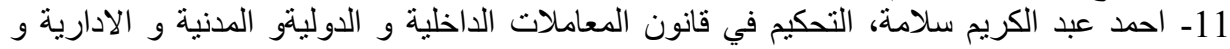

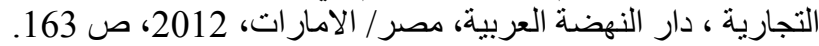

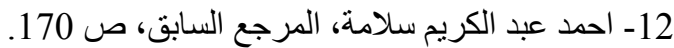

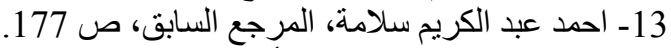

14- جاك دونللي، حقوق الإنسان العالمية، ترجمة مبارك علي عثمان، المكتبة الأكاديمية، الطبعة الثانية،

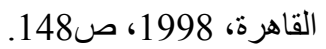

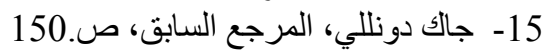

16- إيريك ماريموس، دراسات حول وثائق عالمية و إقليمية، دار الناثنرون، المجلد الثاني، لبنان،

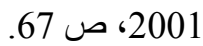

17- جبر سعيد، إنتهاكات حقوق الإنسان وسيكولوجية الابنزاز والاعتداء، علم الكتاب الحديث الطبعة

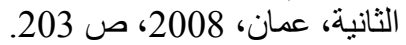

18- مبادئ باريس المتعلقة بالمؤسسات الوطنية لحماية حقوق الانسان و النهوض بهان الإنهان الدصادق عليها

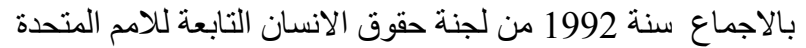

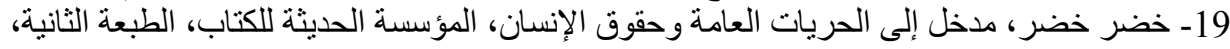

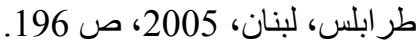

Daniel paul , Revue Général de droit international public et institu de droit de l'homme -20tome2, 1990, p 25

21- إسماعيل معر اف، الوضع الاقليمي العربي في ظل المتغيرات الدولية، المؤسسة الوطنية للاتصال ،

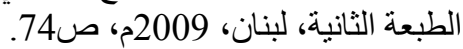

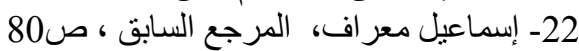

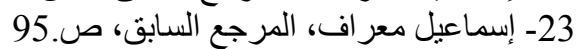

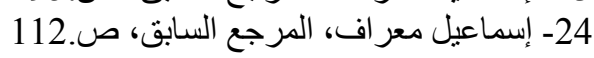




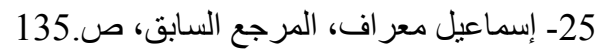

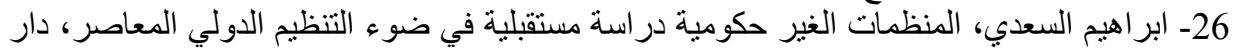

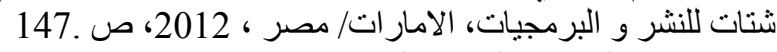

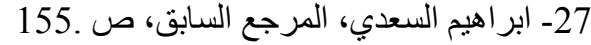

28- سعد الله عمر، مدخل في القانون الدولي لحقوق الإنسان، دار النقافة للنشر و التوزيع، الطبعة ثانبة،

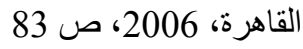

29- سعاد محمد الصباح، حقوق الإنسان بين النظرية والتطبيق، دار سعاد الصباح، الطبعة الأولى،

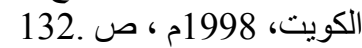

30- سهيل حسين فتلاوب، مدخل إلى حقوق الإنسان، دار النهضة للنشر والتوزيع، الطبعة الثانية،

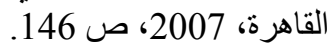

31- عمر بندور، ددخل إلى دراسة حقوق الإنسان و الحريات العامة، ديوان المطبو عات، مجلد الرابع،

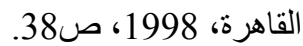

32- عمر صدوق، دراسة في مصادر حقوق الإنسان، ديو ان المكتبة الجامعية، الطبعة الأولى، الجزائر،

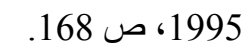

33- عبد العزيز محمد سرحان، القانون الدولي العام، دار النهضة العربية، الطبعة الأولى، القاهرة،

1961م، ص 99.

34- عيسى بيرم، الحريات العامة وحقوق الإنسان، دار المنهل اللبناني، الطبعة الثانية، بيروت، 1998،

ص160.

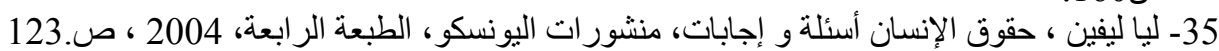

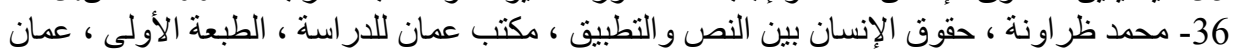

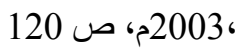

37- محمد محسن، حماية حقوق الإنسان، دار النهضة العربية، الطبعة الأولى، القاهرة، 1992، 